\title{
The Competition Transport of Sodium Ions and Protons in the Cytoplasmic Access Channel of the $\mathrm{Na}^{+}, \mathrm{K}^{+}$-ATPase
}

\author{
V. Yu. Tashkin ${ }^{a}$, A. A. Shcherbakov ${ }^{a}$, H.-J. Apell ${ }^{b}$, and V. S. Sokolov ${ }^{a}$ \\ ${ }^{a}$ Frumkin Institute of Physical Chemistry and Electrochemistry, Russian Academy of Sciences, \\ Leninskii prosp., 31, build. 4, Moscow, 119071 Russia \\ e-mail:sokolovvs@mail.ru \\ ${ }^{b}$ Department of Biology, University of Konstanz, Fach M635, 78457 Konstanz, Germany
}

\begin{abstract}
The changes in capacitance and conductance of lipid bilayer membranes have been studied with adsorbed membrane fragments containing $\mathrm{Na}^{+}, \mathrm{K}^{+}$-ATPase. These changes have been initiated by fast release of protons from a bound form ("caged $\mathrm{H}^{+}$") induced by an UV flash. The changes of the capacitance in the presence of $\mathrm{Na}^{+}, \mathrm{K}^{+}$-ATPase were affected by the frequency of the applied voltage, $\mathrm{pH}$ and the concentration of sodium ions. Addition of sodium ions altered the changes of capacitance caused by a $\mathrm{pH}$ jump in the medium due to caged $\mathrm{H}^{+}$photolysis, and the magnitude and sign of this effect depended on the initial $\mathrm{pH}$. These results are explained by competitive binding of sodium ions and protons to the ion-binding sites of the $\mathrm{Na}^{+}, \mathrm{K}^{+}$-ATPase at its cytoplasmic side. The $\mathrm{pH}$ at which the sign of the sodium ion effect changed allows the evaluation of the $\mathrm{pK}$ of the proton binding site, which is about 7.6.
\end{abstract}

Keywords: sodium pump, electrogenic transport, $\mathrm{Na}^{+}, \mathrm{K}^{+}$-ATPase, caged $\mathrm{H}^{+}$

The $\mathrm{Na}^{+}, \mathrm{K}^{+}$-ATPase is a widely distributed enzyme which pumps the $\mathrm{Na}$ ions out of and $\mathrm{K}$ ions into the cell at the expense of ATP hydrolysis. The generally accepted mechanism of active transport by the $\mathrm{Na}^{+}, \mathrm{K}^{+}$-ATPase - the Albers-Post cycle includes the sequential processing of various steps. The most important feature of the mechanism is the existence of two main conformations of the protein: $\mathrm{E} 1$ and E2, in which the ions have access to the binding sites either from the cytoplasmic or the extracellular medium, respectively. The transition from E1 to E2 is caused by hydrolysis of ATP, and the phosphate transferred from ATP is covalently bound to the protein (phosphorylation of the protein). This phosphate is released during the back transition from E2 to E1. The access of ions to the binding sites is provided by ion access channels, or ion wells [1]. Recent investigations yielded the three-dimensional structure of the $\mathrm{Na}^{+}, \mathrm{K}^{+}$-ATPase in its E2-conformation [2, 3], and detailed structures of the SR Ca ${ }^{2+}$-ATPase in various conformations [4]. However, the structures of ion access channels are not established so far and some questions concerning the mechanism of the function of the $\mathrm{Na}^{+}, \mathrm{K}^{+}$-ATPase remain open.

The study of non steady-state electrogenic transport of sodium ions in the absence of potassium ions yields information about the ion access channels. It has been shown that the channel from the extracellular side of protein is long and narrow, and provides a drop of $70 \%$ of the voltage applied to the membrane, whereas the channel from the cytoplasmic side is short, and provides a drop of much lower part of externally applied voltage [5-8]. The electric current in these channels is caused by the movement of one of the three sodium ions. It was unclear for a long time why the two other ions do not contribute significantly to the electric current. According to one of the hypotheses, instead of charge transfer (and electric current), the binding of these two ions is coupled with the release of protons from amino acids near the binding sites, and due to it a non-electrogenic exchange of sodium ions against protons takes place. The hypothesis is supported by a high homology of these binding sites (which can bind also the potassium ions) with the binding sites of other P-type ATPases (SR Ca ${ }^{2+}$-ATPase and $\mathrm{H}^{+}, \mathrm{K}^{+}-$ ATPase) which perform an exchange transport of metal ions against protons.

The non steady-state electrogenic ion transport can be studied with model lipid bilayer membranes (BLM) with adsorbed membrane fragments containing the $\mathrm{Na}^{+}, \mathrm{K}^{+}$-ATPase. Formerly, the electric signals in such a system were initiated by fast release of ATP from a bound form (caged ATP) by an UV light flash $[10,11]$. The measurement of short-circuit currents as well as small increments of the membrane admittance (capacitance and conductance) in potassium-free medium initiated by fast release of ATP allowed the detailed study of the electrogenic transport of sodium 
<smiles>COc1ccc([N+](=O)[O-])cc1OS(=O)(=O)O[NH3+]</smiles>

Fig. 1. The structure of MNPS (caged $\mathrm{H}^{+}$).

ions in both access channels of $\mathrm{Na}^{+}, \mathrm{K}^{+}$-ATPase [12]. We have shown recently that the ATP-initiated admittance increments can be detected even in a medium which does not contain sodium ions, and that these increments depend on the $\mathrm{pH}$ [13]. These experiments can be explained if one assumes that the $\mathrm{Na}^{+}, \mathrm{K}^{+}$ATPase can transport not only sodium ions but also protons. In physiological conditions the protons exchange against sodium ions without charge transfer, but at low concentration of either of these ions such a transport transforms into electrogenic one: electrogenic proton transport in the absence of sodium ions, or electrogenic sodium ion transport at high $\mathrm{pH}$. However, the analysis of ATP-driven signals did not allow the study of this transport mechanism and its relation to the Albers-Post cycle. As it has been shown, the $\mathrm{Na}^{+}, \mathrm{K}^{+}$-ATPase can transfer the protons in the absence of sodium and potassium ions, hydrolyzing ATP and passing through the E1/E2 conformation change $[14,15]$. So, it remains unclear whether the electric signals observed in our experiments are related to electrogenic transport of ions in the cytoplasmic or extracellular channels.

There is an alternative approach to study proton and sodium ion transport by the $\mathrm{Na}^{+}, \mathrm{K}^{+}$-ATPase in model systems: instead of fast release of ATP, the electric signals are initiated by fast release of protons by photolysis of caged $\mathrm{H}^{+}$. One can expect that in this case there is no E1/E2 conformation change of the $\mathrm{Na}^{+}, \mathrm{K}^{+}$-ATPase. In the absence of ATP the protein will remain in its E1-conformation, while in the presence of ATP it will turn into its E2-conformation. This approach allows measurements of the electric signals coupled with electrogenic transport separately from either the cytoplasmic (without ATP) or extracellular (with ATP) side of the protein. The substances, whose photolysis leads to a shift of $\mathrm{pH}$, have been synthesized and tested in several laboratories [16-18]. In the present investigation these substances were used to study the electrogenic transport by $\mathrm{Na}^{+}, \mathrm{K}^{+}$-ATPase in the BLM model system.

\section{MATERIALS AND METHODS}

Bilayer lipid membranes were formed by the Mueller-Rudin technique from diophytanoyl phosphosphatidyl choline dissolved in $n$-decane in a concentration of $15 \mathrm{mg} / \mathrm{ml}$ on the orifice in the septum of a teflon cell. The aqueous solution contained $\mathrm{NaCl}$ and $\mathrm{MgCl}_{2}$ (Merck, Germany), EDTA (Sigma, USA), EPPS (Sigma, USA), dithiothreithol (Sigma, USA) and N-methyl- $D$-glucamine chloride (NMG) (Sigma, USA) to maintain the chloride concentration as high as necessary for silver-chloride electrodes in the absence of $\mathrm{NaCl}$. In the experiments with the protonophore the solution contained also pentachlorphenol (PCP) (ICN, USA). The contents of the solutions are listed in the legends to the figures. All solutions were prepared with distilled water additionally purified by MILI-Q50 with filter Pure PACK-1 (Thermo Scientific).

Membrane fragments containing the purified $\mathrm{Na}^{+}, \mathrm{K}^{+}$-ATPase were prepared from rabbit kidneys according to the procedure described in [19]. The activity of $\mathrm{Na}^{+}, \mathrm{K}^{+}$-ATPase at $37^{\circ} \mathrm{C}$ was $1300-1700 \mu \mathrm{M}$ of inorganic phosphate per $\mathrm{h}$ per $1 \mathrm{mg}$ protein. Suspensions of the fragments with $\mathrm{Na}^{+}, \mathrm{K}^{+}$-ATPase were stored at $-60^{\circ} \mathrm{C}$ for several months without notable loss of activity. For measurements, the suspension was thawed and stored at $4^{\circ} \mathrm{C}$ for no longer than 2 weeks.

The caged $\mathrm{H}^{+}, 2$-methoxy-5-nitrophenyl sulfate (MNPS), was synthesized by K. Janko (Konstanz, Germany). The molecules of this substance release hydrosulfate after excitation by UV light flash, the dissociation of which leads to acidic shift of $\mathrm{pH}$ in the medium [18].

The electrical measurements were performed using of silver-chloride electrodes which were connected with the solutions in the cell via agar bridges. The solution in the salt bridges was the same as in the cell. To control the formation of the BLM and in the experiments with the protonophore, the membrane capacitance, conductance and the potential of zero current were measured by the method based on the analysis of dynamic current-voltage characteristics, applying periodic triangle wave with a voltage amplitude of $10-$ $50 \mathrm{mV}$ and a frequency of $2-200 \mathrm{~Hz}$. This voltage was applied to one of the electrodes in the BLM cell from the analog output of the ADC/DAC board (L-780, LCard, Russia). The other electrode was connected to the input of a current-voltage converter (Keithkey427 , USA), the output of which was connected to the input of the same ADC/DAC board. The capacitance, conductance and zero-current potential were calculated by the computer software developed by V. Sokolov, and the change of these parameters with time were recorded and stored in the computer. The fast changes of open circuit potential were measured and recorded by a Keithley-301 operational amplifier, the output of which was connected to the input of $\mathrm{ADC} / \mathrm{DAC}$ board.

During measurements of capacitance and conductance increments of the membrane with $\mathrm{Na}^{+}, \mathrm{K}^{+}$ATPase caused by a fast $\mathrm{pH}$ change due to photolysis of caged $\mathrm{H}^{+}$, a periodic sine wave voltage with an amplitude of $50 \mathrm{mV}$ and a frequency of $2-1000 \mathrm{~Hz}$ was applied to the membrane. The measurements were 


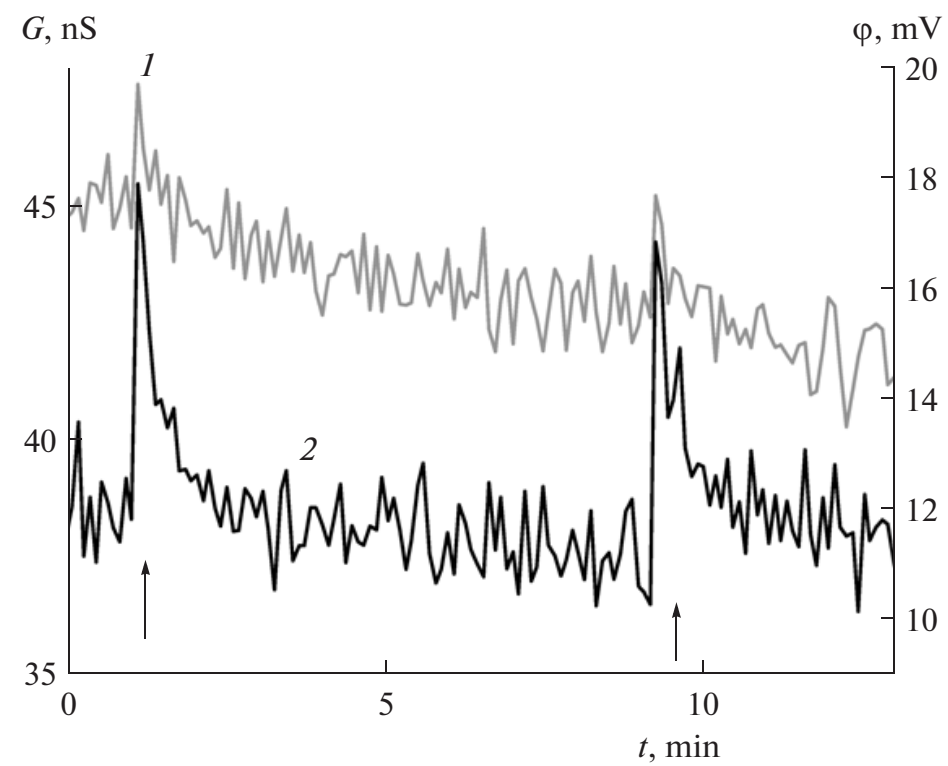

Fig. 2. Changes of conductance (1) and membrane potential (2) of the BLM without membrane fragments in the presence of protonophore pentachlorphenole (PCP) initiated by photolysis of MNPS added into compartment on one side of the membrane. The BLM was formed from diphytanoyl-PC in decane. The aqueous solution contains $12 \mathrm{mM} \mathrm{NMG,} 10 \mathrm{mM} \mathrm{MgCl} 2,10 \mu \mathrm{M}$ PCP, $\mathrm{pH}$ 7.4. The application of the light flashes is marked by arrows.

conducted at room temperature by a technique similar to that developed earlier for measurements of signals caused by fast release of ATP from caged ATP [10, 11], expanded for measurements of small increments of the membrane capacitance and conductance [20]. The cell had two windows: the first one for visual inspection of the BLM and the second one for its illumination by UV light flashes. The light source was a xenon flash lamp with sapphire window FJ-249 (EG\&G, USA). After the BLM was formed, dithiothreitol was added to the solutions in both cell compartments at a final concentration of $1 \mathrm{mM}$, and the suspension of membrane fragments with $\mathrm{Na}^{+}, \mathrm{K}^{+}$-ATPase was added into the trans-compartment with respect to the light source. The protein concentration in the cell was 20 $\mu \mathrm{g} / \mathrm{ml}$. The adsorption of the membrane fragments on the BLM was controlled as the decrease of the membrane capacitance. It was completed after about $2 \mathrm{~h}$. The electric signals generated by the $\mathrm{Na}^{+}, \mathrm{K}^{+}$-ATPase were recorded after the adsorption was completed and $750 \mu \mathrm{M}$ caged $\mathrm{H}^{+}$was added into the compartment with the membrane fragments.

\section{RESULTS AND DISCUSSION}

Before the influence the $\mathrm{pH}$ shifts on the function of the $\mathrm{Na}^{+}, \mathrm{K}^{+}$-ATPase was studied, we performed calibration experiments to measure the $\mathrm{pH}$ shift near the BLM due to photolysis of caged $\mathrm{H}^{+}$, as well as control experiments with effects of these $\mathrm{pH}$ shifts on the change of the membrane capacitance without $\mathrm{Na}^{+}, \mathrm{K}^{+}$-ATPase.
To evaluate the $\mathrm{pH}$ shift near the BLM, we measured the potential across the membrane which became selective to protons after the addition of protonophore PCP. The kinetics of the potential change is presented in Fig. 2. The potential shifted after the UV light flash and was restored to its initial value within about 2 min. A similar kinetics was observed for the membrane conductance, which increased after the light flash and then was restored to its initial value. The next light flash led to the same effects, thus allowing several measurements with the same membrane. The change of the membrane potential and conductance can be explained by a $\mathrm{pH}$ shift due to photolysis of caged $\mathrm{H}^{+}$. The conductance is increased after the light flash due to the $\mathrm{pH}$ dependence in the presence of the protonophore, which is non-monotonic and, in general, has a bell-type shape [22]. If the initial $\mathrm{pH}$ is higher than the position of the maximum of this bell (that is true in our case, where the maximum of the BLM conductance with PCP is at about pH 5 [23]), the conductance is proportional to the proton concentration in the solution, and the decrease of $\mathrm{pH}$ due to photolysis of caged $\mathrm{H}^{+}$leads to an increase of the conductance. The restoration of the potential and conductance takes place due to exchange of the small solution volume near the membrane in which the $\mathrm{pH}$ was decreased, with the unperturbed bulk volume of the solution. These experiments indicate that the $\mathrm{pH}$ shift after light flash in presence of caged $\mathrm{H}^{+}$is transient, and that its value is about a few hundredths parts of a $\mathrm{pH}$ unit. 


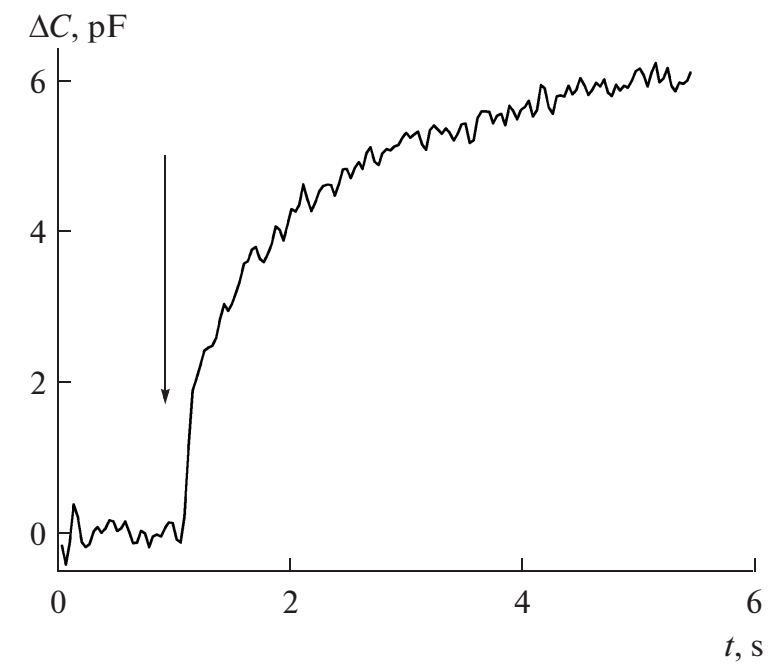

Fig. 3. Change of the capacitance of the BLM without membrane fragments initiated by photolysis of MNPS added into compartment on one side of the membrane. The BLM was formed from diphytanoyl PC in decane. The aqueous solution contains $0.05 \mathrm{mM}$ EPPS, $100 \mathrm{mM}$ $\mathrm{NaCl}, \mathrm{pH}$ 7.0. The time of the light flash is marked by an arrow.

In control experiments without $\mathrm{Na}^{+}, \mathrm{K}^{+}$-ATPase, the light flash in the presence of caged $\mathrm{H}^{+}$led to a change of the membrane capacitance (Fig. 3), which depends on the frequency of the applied voltage. The shift of the membrane capacitance can be caused by a change of its thickness or of its dielectric permeability due to a protonation of the phospholipids as well as due to adsorption/desorption of caged $\mathrm{H}^{+}$or its photoproducts. The latter possibility can be tested by measurements of the change of the boundary potential of the lipid bilayer initiated by the light flash. The change of the boundary potential due to photolysis of MNPS was measured by an electrometer as a fast shift of the open circuit potential (Fig. 4). This shift can be assigned to a change of the boundary potential, because it proceeds in a time interval much shorter than the time necessary to establish the diffusion equilibrium potential $[24,25]$. The shift of the potential detected in the experiments was very low (about $0.1 \mathrm{mV}$ ); therefore, one can conclude that the change of the BLM surface charge due to photolysis of caged $\mathrm{H}^{+}$is negligible. It excludes the possibility of an electrostatic mechanism, according to which the change of the membrane capacitance is caused by electrostriction due to an intramembrane electric field: the electrostrictional change of the membrane capacitance evaluated from such a small change of the boundary potential should be much lower than that measured after the light flash (Fig. 3). Because of the negligible shift of the boundary potential after the light flash we can neglect the adsorption of caged $\mathrm{H}^{+}$and its photoproducts on the membrane, in agreement with conclusions made in [18]. Therefore, the shift of $\mathrm{pH}$ in the solution

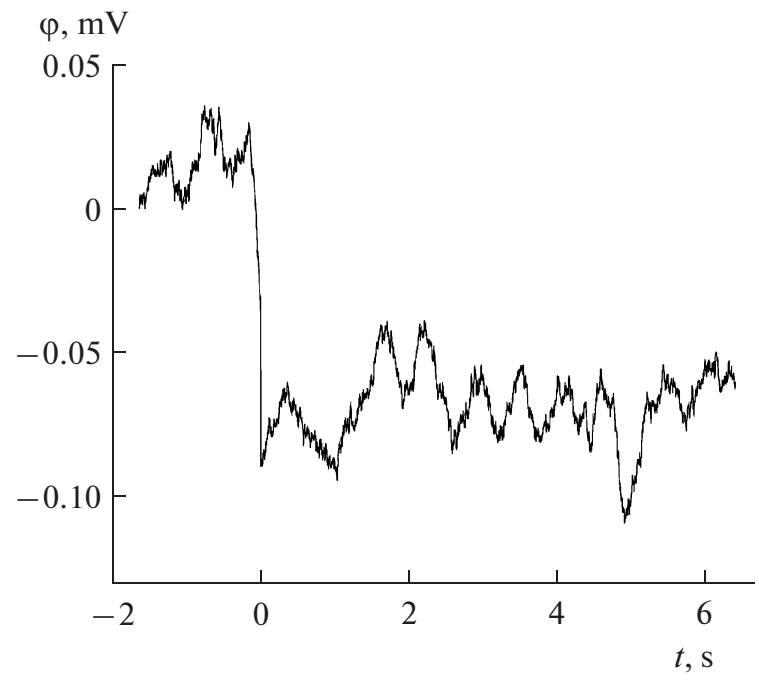

Fig. 4. Change of membrane (boundary) potential of BLM without membrane fragments initiated by photolysis of MNPS added into compartment on one side of the membrane. The aqueous solution contains $12 \mathrm{mM}$ NMG, $10 \mathrm{mM}$ $\mathrm{MgCl}_{2}, \mathrm{pH}$. The light flash was applied at zero time.

near the membrane is the only factor which can lead to the capacitance change. This change of membrane capacitance could be caused by protonation of phospholipids but the related shift of the BLM surface charge must be negligible.

We have shown that in the absence of $\mathrm{Na}^{+}, \mathrm{K}^{+}-$ ATPase significant changes of the membrane capacitance are observed after photolysis of caged $\mathrm{H}^{+}$, and the mechanism of this effect is not clear. This complicates the application of caged $\mathrm{H}^{+}$to study the $\mathrm{Na}^{+}, \mathrm{K}^{+}-$ ATPase. The standard way to extract the electric signals related to the $\mathrm{Na}^{+}, \mathrm{K}^{+}$-ATPase function is to determine the difference of the electric currents recorded with native protein and after its inhibition [26]. In our case, instead of the inhibition of the $\mathrm{Na}^{+}, \mathrm{K}^{+}$-ATPase, we decided to analyze the competition of sodium ions with protons at the binding sites of the $\mathrm{Na}^{+}, \mathrm{K}^{+}$-ATPase. If such a competition exists, the addition of sodium ions should suppress the capacitance increments caused by proton movement in the $\mathrm{Na}^{+}, \mathrm{K}^{+}$-ATPase, because a fraction of the binding sites will be occupied by sodium ions. The most significant effect can be expected at sodium concentration higher than that corresponding to a semi-saturation of the binding sites. The concentration at which half of the binding sites are occupied is about $4 \mathrm{mM}[27,28]$. Therefore, we assumed that at $10 \mathrm{mM} \mathrm{Na}^{+}$in the solution, most of the binding sites will be occupied, and the capacitance and conductance increments caused by proton movements in cytoplasmic channel of $\mathrm{Na}^{+}, \mathrm{K}^{+}$-ATPase should be suppressed.

The first series of experiments with the $\mathrm{Na}^{+}, \mathrm{K}^{+}-$ ATPase was carried out at four values of $\mathrm{pH}(7.2,7.4$, 


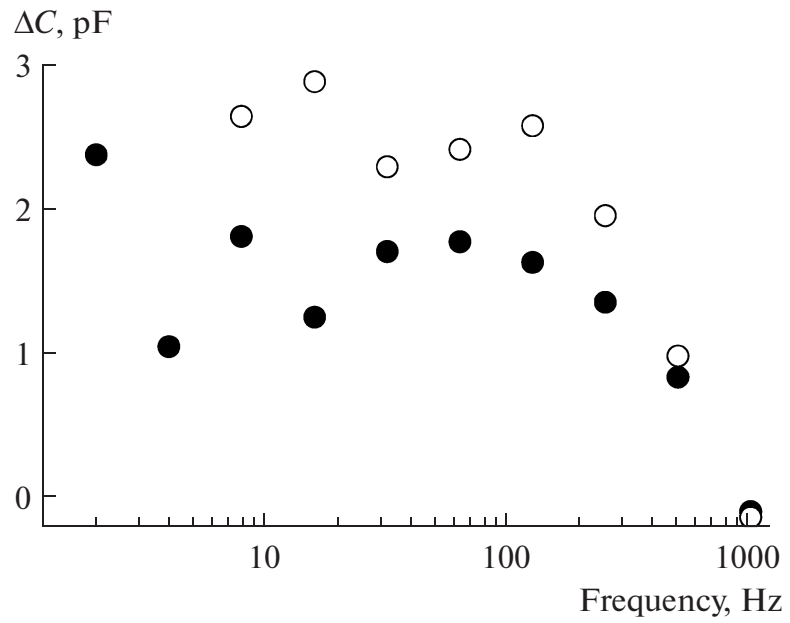

Fig. 5.Frequency dependencies of the capacitance increments of BLM with adsorbed membrane fragments containing $\mathrm{Na}^{+}, \mathrm{K}^{+}$-ATPase initiated by photolysis of MNPS added into compartment on one side of the membrane in the absence (dark symbols) and presence (open symbols) of $\mathrm{Na}^{+}$ions. The aqueous solution contains $12 \mathrm{mM} \mathrm{NMG}$, $10 \mathrm{mM} \mathrm{MgCl} 2,0.1 \mathrm{mM}$ EDTA, pH 7.4.

7.6 and 7.9) with frequencies of the sine voltage in the range from 2 to $1024 \mathrm{~Hz}$. In each experiment, after the frequency dependence was recorded, $\mathrm{NaCl}$ was added in a concentration of 4 or $10 \mathrm{mM}$ to the cell compartment containing the membrane fragments with $\mathrm{Na}^{+}, \mathrm{K}^{+}$-ATPase, and then the next frequency dependence was recorded. At $\mathrm{pH} 7.2$ the capacitance had a typical frequency dependence both in the absence and in the presence of sodium ions with a plateau at low frequencies, a decrease above $100 \mathrm{~Hz}$ and a drop to zero at $1000 \mathrm{~Hz}$ (Fig. 5). In the presence of $\mathrm{Na}^{+}$the capacitance increments were lower at all frequencies than in the absence of $\mathrm{Na}^{+}$(the effective sodium concentration in nominal absence of $\mathrm{NaCl}$ was not zero but about $0.75 \mathrm{mM}$, because we used the sodium salt of caged $\mathrm{H}^{+}$).

In another series of experiments, the capacitance increments were measured at a fixed frequency $(64 \mathrm{~Hz})$ after sequential additions of sodium ions (Fig. 6). To check if the effect of sodium ions is due to the function of the $\mathrm{Na}^{+}, \mathrm{K}^{+}$-ATPase, control experiments were performed, in which the enzyme was inhibited by vanadate. It has been shown that vanadate inhibits the electrogenic transport of sodium ions in cytoplasmic channel of $\mathrm{Na}^{+}, \mathrm{K}^{+}$-ATPase [29]. In the presence of this inhibitor, the effect of sodium ions on the capacitance increments triggered by photolysis of caged $\mathrm{H}^{+}$ has not been observed (Fig. 6). Similar experiments were conducted at various $\mathrm{pH}$ (from 7 to 8 ). At each $\mathrm{pH}$ the capacitance increments reached the plateau at sodium ion concentrations higher than $3-4 \mathrm{mM}$. This observation agrees with the assumption that sodium

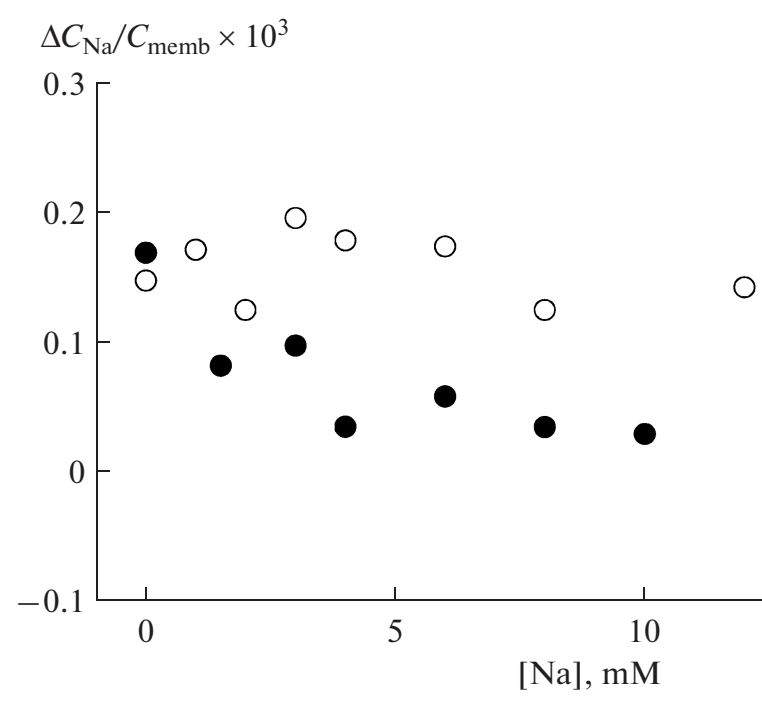

Fig. 6. Capacitance increments of BLM with adsorbed membrane fragments containing $\mathrm{Na}^{+}, \mathrm{K}^{+}$-ATPase initiated by photolysis of MNPS measured at $64 \mathrm{~Hz}$ as a function of concentration of sodium ions in the presence (open symbols) and absence (black symbols) of $10 \mu \mathrm{M}$ vanadate. The aqueous solution contains $12 \mathrm{mM}$ NMG, $10 \mathrm{mM}$ $\mathrm{MgCl}_{2}, \mathrm{pH} 8$.

ions suppress the capacitance increments initiated by a $\mathrm{pH}$ decrease. The quantitative effect of sodium ion concentrations on the capacitance increments measured at $64 \mathrm{~Hz}$ and at all $\mathrm{pH}$ values was determined as a difference between plateau value and that at $0 \mathrm{mM}$ $\mathrm{NaCl}$. The $\mathrm{pH}$-dependence of this difference is shown in Fig. 7; it was normalized to the capacitance of the membrane (which is proportional to its area) to decrease scattering of the data obtained on different membranes. As is shown in Fig. 7, the dependence of the sodium effect on $\mathrm{pH}$ is non-monotonic. At low $\mathrm{pH}$ the sodium effect is positive (i.e., the addition of $\mathrm{NaCl}$ leads to an increase of the capacitance increments upon photolysis of caged $\mathrm{H}^{+}$), while at high $\mathrm{pH}$ this effect becomes negative (the capacitance increments decrease with the addition of $\mathrm{NaCl}$ ).

These results can be explained with the help of the model of competition between sodium ions and protons in cytoplasmic channel of the $\mathrm{Na}^{+}, \mathrm{K}^{+}$-ATPase. This model is a generalized model of the electrogenic transport of sodium ions developed in [12]. The simple application of the approach based on this model, which accounts for the kinetics of sodium and proton transport, leads to a considerable complication of the equations and requires many additional parameters. However, it is possible to obtain very simple equations that describe the equilibrium distribution of these ions in the channel (in the approximation of low voltage frequencies). The model in [12] describes the translocation of one of the sodium ions which was assumed as an electrogenic step, which takes place with respect to the binding site unsuitable for protons. Now we will 


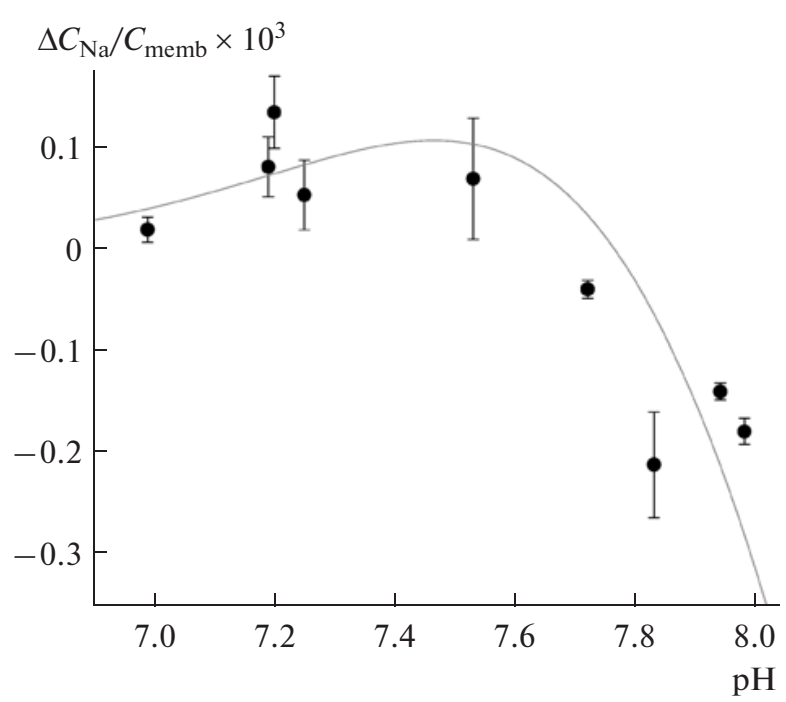

Fig. 7. Differences (in the absence and presence of 4-10 mM $\mathrm{NaCl}$ ) of the capacitance increments of BLM with adsorbed membrane fragments containing $\mathrm{Na}^{+}, \mathrm{K}^{+}$ATPase initiated by photolysis of MNPS added into compartment on one side of the membrane as a function of the $\mathrm{pH}$. The aqueous solution contained $12 \mathrm{mM}$ NMG, 0.014 $\mathrm{mM}$ EDTA, $0.1 \mathrm{mM}$ buffer. The solid line is theoretical curve calculated according to Eq. (4) with the parameters listed in the text.

consider a similar model for the two other binding sites, which have a negative charge, according to published data, and can bind not only sodium ions but also protons. For simplicity, both binding sites will be assumed to be identical. If any of them binds either a sodium ion or a proton (because of competition, the simultaneous binding of both ions in the same site is excluded), the net charge of the occupied site is zero. The electric currents generated by ion translocation in the channel can be derived from the change of density/concentration of the free, i.e., negatively charged binding sites. The conservation equation of the binding sites can be written as

$$
N_{0}+N_{\mathrm{Na}}+N_{\mathrm{H}}=N \text {, }
$$

where $N$ is the total amount of binding sites in the $\mathrm{Na}^{+}, \mathrm{K}^{+}$-ATPase in the membrane, $N_{0}$ is the number of free binding sites, $N_{\mathrm{Na}}$ the number of binding sites occupied by sodium ions, and $N_{\mathrm{H}}$ is the number of binding sites occupied by protons. When the numbers of binding sites, $N_{0}, N_{\mathrm{Na}}$, and $N_{\mathrm{H}}$, are divided by $N$, they can be replaced by their dimensionless fractions, $\Theta, \Theta_{0}, \Theta_{\mathrm{Na}}, \Theta_{\mathrm{H}}$ :

$$
\Theta_{0}+\Theta_{\mathrm{Na}}+\Theta_{\mathrm{H}}=1 \text {. }
$$

In the equilibrium state, the fractions of sites with bound ions can be derived by the electric potential, $\varphi$, applied to the membrane by the Boltzmann equation

$$
\begin{aligned}
\Theta_{\mathrm{Na}} & =\frac{\left[\mathrm{Na}^{+}\right]}{K_{\mathrm{Na}}} \exp (-\alpha \beta \varphi) \Theta_{0}, \\
\Theta_{\mathrm{H}} & =\frac{\left[\mathrm{H}^{+}\right]}{K_{\mathrm{H}}} \exp (-\alpha \beta \varphi) \Theta_{0},
\end{aligned}
$$

where $K_{\mathrm{Na}}$ and $K_{\mathrm{H}}$ are the binding constants of $\mathrm{Na}^{+}$ and $\mathrm{H}^{+}$ions in the sites, respectively, $\alpha$ is the fraction of the voltage applied to the membrane which influences the distribution of ions in the channel of $\mathrm{Na}^{+}, \mathrm{K}^{+}$-ATPase [12], $\beta=\mathrm{e} / k T$. The fraction of free binding sites $\Theta_{0}$ can be derived from these equations as

$$
\Theta_{0}=\frac{1}{1+\overline{N a} \exp (-\alpha \beta \varphi)+\bar{H} \exp (-\alpha \beta \varphi)},
$$

where $\overline{N a}=\left[\mathrm{Na}^{+}\right] / K_{\mathrm{Na}}, \bar{H}=\left[\mathrm{H}^{+}\right] / K_{\mathrm{H}}$ are the dimensionless concentrations of ions normalized by their binding constants. The total charge of binding sites, $Q$, is equal to $\Theta_{0}$ multiplied to total number of protein molecules and elementary charge

$$
Q=\frac{N e}{1+\overline{N a} \exp (-\alpha \beta \varphi)+\bar{H} \exp (-\alpha \beta \varphi)} .
$$

The contribution $C$ to the membrane capacitance caused by movements of ions in the $\mathrm{Na}^{+}, \mathrm{K}^{+}$-ATPase in the limit of zero frequency is, according to [12, 20], equal to the voltage derivative of charge transferred by the external circuit due to voltage change. It can be found as a derivation of (1) with respect to $\varphi$

$$
\begin{gathered}
C=\alpha \frac{d Q}{d \varphi} \\
=\frac{N \alpha^{2} e^{2}[\overline{N a} \exp (-\alpha \beta \varphi)+\bar{H} \exp (-\alpha \beta \varphi)]}{k T[1+\overline{N a} \exp (-\alpha \beta \varphi)+\bar{H} \exp (-\alpha \beta \varphi)]^{2}} .
\end{gathered}
$$

The dependencies of $C$ on $\overline{N a}$ and $\bar{H}$ according to this equation are presented in Fig. 8a. In the experiments with caged $\mathrm{H}^{+}$we measured the capacitance increments with the decrease of the $\mathrm{pH}$ in the medium. It can be determined from Eq. (3) as its derivation with respect to $\bar{H}$

$$
\Delta C=\frac{d C}{d \bar{H}} \Delta \bar{H}
$$

$$
=\frac{N \alpha^{2} e^{2}[1-\overline{N a} \exp (-\alpha \beta \varphi)-\bar{H} \exp (-\alpha \beta \varphi)]}{k T[1+\overline{N a} \exp (-\alpha \beta \varphi)+\bar{H} \exp (-\alpha \beta \varphi)]^{3}} \times \Delta \bar{H} \text {. }
$$

To plot the theoretical curves in coordinates allowing their comparison with the experimental data in Fig. 7, it is convenient to use as abscissa the dimensionless concentration of protons which can be derived by the expression

$$
\mathrm{pH}-\mathrm{pK}=-\log (\bar{H}),
$$




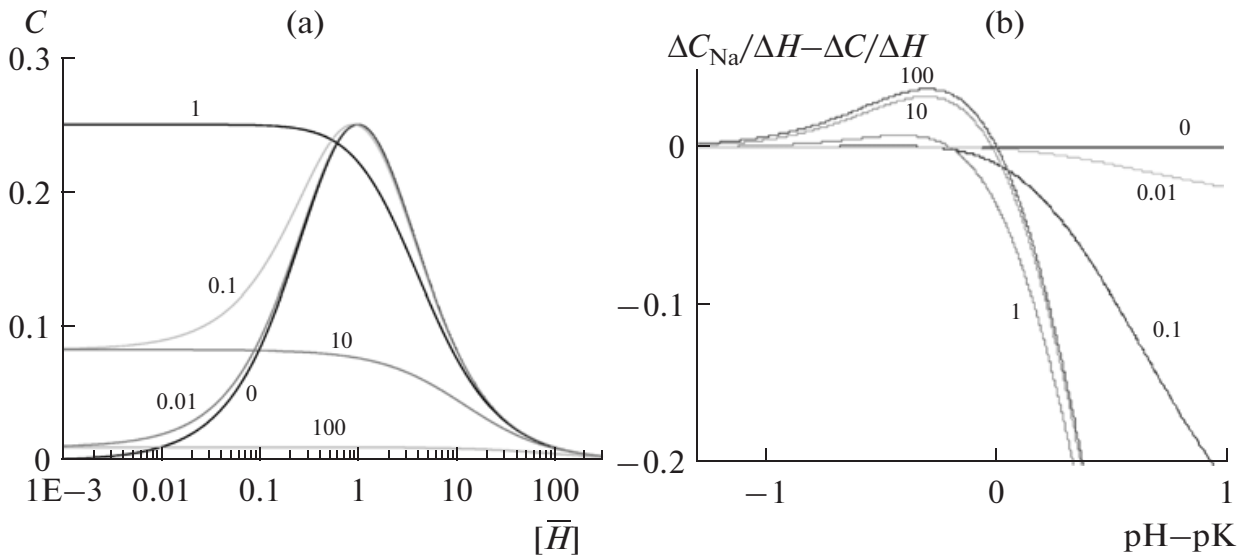

Fig. 8. (a) Theoretical dependencies of the capacitance increments at the zero-frequency limit of the applied voltage as a function of the normalized protons concentration, $[\bar{H}]$, of the capacitance increments at various normalized concentrations of $\mathrm{Na}^{+}$. The curves are plotted according to Eq. (3). The values on the vertical axis are plotted in dimensionless units $\frac{C k T}{N \alpha^{2} e^{2}}$. (b) The effect of $\mathrm{Na}^{+}$on the capacitance increments (in dimensionless units of $\frac{\Delta C k T}{N \alpha^{2} e^{2} \Delta \bar{H}}$ ) at the zero-frequency limit of the applied voltage in response to the decrease of $\mathrm{pH}$. Normalized concentrations of $\mathrm{Na}^{+}$are shown above the curves. The curves are plotted according to Eq. (4) with the abscissa in units $\mathrm{pH}-\mathrm{pK}$ (Eq. (5)).

where $\mathrm{pK}=-\log \left(\mathrm{K}_{\mathrm{H}}\right)$. Figure $8 \mathrm{~b}$ presents the dependencies of the capacitance increments on $\mathrm{pH}$ and sodium concentrations using Eq. (5). Figure $8 \mathrm{~b}$ shows that the addition of sodium ions has an effect of various signs that depends on the concentration of these ions and $\mathrm{pH}$. The shape closest to the experimental curve shown in Fig. 7 is represented by the curve with high $\overline{N a}$, not less than 10 . The theoretical curve was fitted to the experimental data using the least square method. The value of $\overline{N a}$ tends to grow to infinity, therefore it was limited to 10 . As a result, the theoretical curve in Fig. 7 was fitted with the following parameter values: $\mathrm{pK}=7.6, \overline{N a}=10, \frac{N \alpha^{2} e^{2}}{k T} \Delta \bar{H}=1.2 \mathrm{pF}$. The agreement of the theoretical curve with the experiment leads to the conclusion that $\mathrm{pK}$ of at least one of the binding sites is about 7.6. The accuracy of the measurements is not good enough to check the assumption that there are two similar binding sites (or that there is only a single binding site). To answer the question whether there is the second binding site with a $\mathrm{pK}$ different from 7.6, additional measurements in a wider $\mathrm{pH}$ range are necessary. The accuracy of the measurements was not high enough to determine the binding constant for sodium ions. Its normalized value of 10 used in our set of parameters can be regarded rather as a lower limit, because, as follows from Fig. 8b, the theoretical curve at $\overline{N a}=10$ does not significantly differ from the asymptotic one plotted for $\overline{\mathrm{Na}} \rightarrow \infty$. The third parameter found by the fitting routine can be used to evaluate the number of proteins involved in the competing proton transport. This evaluation is not exact, because assumptions have been used about the structure of the experimental system. However, it can be useful to check, whether the amount of the proteins found from the evaluation with reasonable assumptions agree with respect to the density of proteins in the membrane fragments known from published data. In the evaluation we used the calibration data (Fig. 2), according to which the $\mathrm{pH}$ decrease after the light flash is about 0.05 . The calibration was performed at $\mathrm{pH} 7.4$, which is almost equal to $\mathrm{pK} 7.6$ found by our fit of the data; therefore, one can assume that $\bar{H} \approx 1$, and finally, $\Delta \bar{H}=2.303 \bar{H} \times \Delta p H \approx 0.1$. Taking $\frac{e^{2}}{k T} \Delta \bar{H}=$ $6.3 \times 10^{-19} \mathrm{~F}$, one finds $N \alpha^{2}=1.9 \times 10^{6}$. According to [12], coefficient $\alpha$ is equal to the product of the ratio of capacitances of the BLM and the membrane fragments, which we assess to be 0.3 , and the dielectric coefficient (the relative depth of the ion access channel in the protein), which we also assess to be 0.3 . Finally, the total amount of the proteins is $N=2 \times 10^{8}$. Taking the area of membrane equal to $1 \mathrm{~mm}^{2}$, the surface density of binding sites can be found approximately as $2 \times 10^{14}$ sites per $\mathrm{m}^{2}$. The density of the proteins in the membrane fragments is also unknown, but for our rough approximation it can be taken from electron microscopy data as 3400 proteins per $\mu \mathrm{m}^{2}$ [30], or $3.4 \times 10^{15}$ proteins per $\mathrm{m}^{2}$. The evaluation shows that the capacitance increments observed in the experiments are caused by the action of about $6 \%$ of the 
maximal amount of proteins in the membrane. Taking into account that the membrane fragments with proteins do not cover the total membrane area, one can conclude that the density of proteins obtained from the evaluation agrees within one order of magnitude with the density known from the literature.

It should be noted that the capacitance increments drop with frequency to the range of low values. The frequency of the steepest decrease of the capacitance characterizes the rate of exchange of ions in the channel (analogous to [12], where the characteristic frequency is equal to the sum of forward and back rate constants of ion exchange between the solution and ion-binding sites in the $\mathrm{Na}^{+}, \mathrm{K}^{+}$-ATPase). However, the translocation of ions in the channel, if considered as a (forced) migration in the electric field, should be much faster than it can be expected from our experiments. In the model describing the exchange of sodium ions in the extracellular channel of the $\mathrm{Na}^{+}, \mathrm{K}^{+}$-ATPase, the low characteristic frequency has been explained by the existence of a slow non-electrogenic step limiting the rate of whole process. Such a step was assumed to be the conformation transition E1/E2 of $\mathrm{Na}^{+}, \mathrm{K}^{+}$-ATPase. However, such step may not be assumed in the case of proton transport in cytoplasmic channel of $\mathrm{Na}^{+}, \mathrm{K}^{+}$-ATPase. Perhaps, the low corner frequency is caused by potential barriers for $\mathrm{H}^{+}$ translocation in the cytoplasmic channel. A similar barrier has been assumed also in the model of the $\mathrm{Na}^{+}$ movement to explain the frequency dependence of capacitance increment $[12,21]$. The alternative to a potential barrier in the access channel can be a barrier in the water/membrane interface, because the applied $\mathrm{pH}$ change is present in bulk water solution, while the protons have to diffuse through membrane/water interface prior to their binding to $\mathrm{Na}^{+}, \mathrm{K}^{+}$-ATPase.

\section{ACKNOWLEDGMENTS}

The work was supported by the Program Molecular and Cell Biology of the RAS Presidium.

\section{REFERENCES}

1. Lauger P. 1991. Electrogenic ion pumps. Sunderland, Massachusetts, USA: Sinauer Associates, Inc.

2. Morth J.P., Pedersen B.P., Toustrup-Jensen M.S., Sorensen T.L., Petersen J., Andersen J.P., Vilsen B., Nissen P. 2007. Crystal structure of the sodium-potassium pump. Nature. 450. 1043-1049.

3. Ogawa H., Shinoda T., Cornelius F., Toyoshima C. 2009. Crystal structure of the sodium-potassium pump $\left(\mathrm{Na}^{+}, \mathrm{K}^{+}\right.$-ATPase) with bound potassium and ouabain. Proc. Natl. Acad. Sci. USA. 106. 13742-13747.

4. Toyoshima C. 2009. How $\mathrm{Ca}^{2+}$-ATPase pumps ions across the sarcoplasmic reticulum membrane. Biochim. Biophys Acta. 1793, 941-946.

5. Holmgren M., Wagg J., Bezanilla F., Rakowski R.F., De Weer P., Gadsby D.C. 2000. Three distinct and sequential steps in the release of sodium ions. Nature. 403, 898-901.

6. Rakowski R.F., Gadsby D.C., De Weer P. 1997. Voltage dependence of the Na/K pump. J. Membrane Biol. 155, $105-112$.

7. Gadsby D.C., Rakowski R.F., De Weer P. 1993. Extracellular access to the Na,K-pump: Pathway similar to ion channel. Science. 260, 100-103.

8. Apell H.J. 2004. How do P-type ATPases transport ions? Bioelectrochemistry. 63, 149-156.

9. Apell H.J., Diller A. 2002. Do $\mathrm{H}^{+}$ions obscure electrogenic $\mathrm{Na}^{+}$and $\mathrm{K}^{+}$binding in the E1 state of the $\mathrm{Na}, \mathrm{K}-$ ATPase? FEBS Lett. 532, 198-202.

10. Fendler K., Grell E., Haubs M., Bamberg E. 1985. Pump currents generated by the $\mathrm{Na}^{+}, \mathrm{K}^{+}$-ATPase from kidney on black lipid membranes. EMBO J. 4, 30793085.

11. Borlinghaus R., Apell H.J., Lauger P. 1987. Fast charge translocations associated with partial reactions of the $\mathrm{Na}, \mathrm{K}$-pump. I. Current and voltage transients after photochemical release of ATP. J. Membrane Biol. 97, 161-178.

12. Sokolov V.S., Shcherbakov A.A., Lenz A.A., Chizmadzhev Yu.A., Apell H.-J. 2008. Electrogenic transport of sodium ions in cytoplasmic and extracellular ion access channels of $\mathrm{Na}^{+}, \mathrm{K}^{+}$-ATPase probed by admittance measurement technique. Biochemistry (Moscow) Suppl. Ser. A: Membrane and Cell Biology. 2, 161-180.

13. Grishanin K.O., Tashkin V.Yu.T., Lenz A.A., Apell H.J., Sokolov V.S. Involvement of protons in the ion transport cycle of $\mathrm{Na}^{+}, \mathrm{K}^{+}$-ATPase. Biol. Membranes. 27, 512-518.

14. Apell H.J., Benz G., Sauerbrunn D. 2010. Proton diet for the sodium pump. Biochemistry. 50, 409-418.

15. Polvani C., Blostein R. 1988. Protons as substitutes for sodium and potassium in the sodium pump reaction. J. Biol. Chem. 263, 16757-16763.

16. Geissler D., Antonenko Y.N., Schmidt R., Keller S., Krylova O.O., Wiesner B., Bendig J., Pohl P., Hagen V. 2005. (Coumarin-4-yl)methyl esters as highly efficient, ultrafast phototriggers for protons and their application to acidifying membrane surfaces. Angew. Chem. Int. Ed. Engl. 44, 1195-1198.

17. Serowy S., Saparov S.M., Antonenko Y.N., Kozlovsky W., Hagen V., Pohl P. 2003. Structural proton diffusion along lipid bilayers. Biophys. J. 84, 1031-1037.

18. Fibich A., Janko K., Apell H.J. 2007. Kinetics of proton binding to the sarcoplasmic reticulum Ca-ATPase in the E1 state. Biophys. J. 93, 3092-3104.

19. Jorgensen P.L. 1974. Isolation of the Na,K-ATPase. Meth. Enzymol. 32, 277-290.

20. Sokolov V.S., Stukolov S.M., Darmostuk A.S., Apell H.J. Study of electrogenic transport of sodium ions inside the Na,K-ATPase by means of membrane capacitance measurements. Biol. Membranes. 14, 529-548.

21. Sokolov V.S., Ayuyan A.G., Apell H.J. 2001. Assignment of charge movements to electrogenic reaction steps of Na,K-ATPase by analysis of salt effects on the kinetics of charge movements. Eur. Biophys. J. 30, 515527. 
22. Markin V.S., Chizmadzhev Yu.A. 1974. Indutsirovannyi ionnyi transport (Induced ion transport). Moscow, Nauka.

23. Smejtek P., Hsu K., Perman W.H. 1976. Electrical conductivity in lipid bilayer membranes induced by pentachlorophenol. Biophys. J. 16, 319-336.

24. McLaughlin S.G.A. 1977. Current topic in membrane and transport. Eds. Bronner F., Kleinzeller A. New York, etc. 9, 71-144.

25. Sokolov V.S., Mirsky V.M. 2004. Ultrathin electrochemical chemo- and biosensors: Technology and performance. Ed. Mirsky V.M. Heidelberg: Springer-Verlag, p. 255-291.

26. Nakao M., Gadsby D.C. 1986. Voltage dependence of $\mathrm{Na}$ translocation by the $\mathrm{Na} / \mathrm{K}$ pump. Nature. 323, 628-630.

27. Schneeberger A., Apell H.J. 2001. Ion selectivity of the cytoplasmic binding sites of the Na,K-ATPase. II. Competition of various cations. J. Membrane Biol. 179, 263-273.
28. Schneeberger A., Apell H.J. 1999. Ion selectivity of the cytoplasmic binding sites of the Na,K-ATPase. I. Sodium binding is associated with a conformational rearrangement. J. Membrane Biol. 168, 221-228.

29. Pintschovius J., Fendler K., Bamberg E. 1999. Charge translocation by the $\mathrm{Na}^{+} / \mathrm{K}^{+}$-ATPase investigated on solid supported membranes: Cytoplasmic cation binding and release. Biophys. J. 76, 827-836.

30. Deguchi N., Jorgensen P.L., Maunsbach A.B. 1977. Ultrastructure of the sodium pump. Comparison of thin sectioning, negative staining and freeze-fracture of purified membrane-bound $\left(\mathrm{Na}^{+}, \mathrm{K}^{+}\right)$-ATPase. J. Cell Biol. 75, 619-634.

31. Sokolov V.S., Stukolov S.M., Darmostuk A.S., Apell H.J. 1998. Influence of sodium concentration on changes of membrane capacitance associated with the electrogenic ion transport by the Na,K-ATPase. Eur. Biophys. J. 27, 605-617. 